Research Paper

\title{
Low Expression of CDK5 and p27 Are Associated with Poor Prognosis in Patients with Gastric Cancer
}

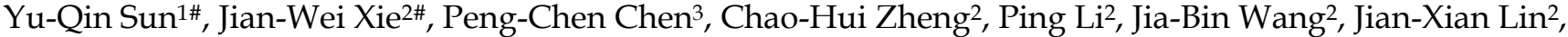 \\ Jun $\mathrm{Lu}^{2}$, Qi-Yue Chen², Long-Long $\mathrm{CaO}^{2}$, Mi Lin², Ru-Hong Tu², Yao Lin ${ }^{3 凶}$ and Chang-Ming Huang ${ }^{2}$
}

1. Department of Gastric Surgery, Fujian Medical University Union Hospital, No.29 Xinquan Road, Fuzhou 350001, Fujian Province, People's Republic of China; College of Life Sciences, Fujian Normal University, Qishan Campus, Fuzhou 350108, Fujian Province, People's Republic of China.

2. Department of Gastric Surgery, Fujian Medical University Union Hospital, No.29 Xinquan Road, Fuzhou 350001, Fujian Province, People's Republic of China;

3. College of Life Sciences, Fujian Normal University, Qishan Campus, Fuzhou 350108, Fujian Province, People's Republic of China.

\# These authors contributed equally to this article.

$\triangle$ Corresponding authors: Chang-Ming Huang, Professor, Department of Gastric Surgery, Fujian Medical University Union Hospital, No.29 Xinquan Road, Fuzhou 350001 Fujian Province, China. hcmlr2002@163.com; Yao Lin, Professor, College of Life Sciences, Fujian Normal University, Qishan Campus, Fuzhou 350108, Fujian Province, People’s Republic of China.yaolin@fjnu.edu.cn; yaolinfjfz@gmail.com

() Ivyspring International Publisher. Reproduction is permitted for personal, noncommercial use, provided that the article is in whole, unmodified, and properly cited. See http://ivyspring.com/terms for terms and conditions.

Received: 2015.12.22; Accepted: 2016.03.15; Published: 2016.05.25

\begin{abstract}
Several previous studies have demonstrated that CDK5 or p27 expression in gastric cancer are associated with overall survival. We have previously reported that tumor suppressive function of CDK5 is related to $\mathrm{p} 27$. The aim of this study was to investigate correlation between the clinicopathological parameters and overall survival with different CDK5/p27 expression statuses in 244 gastric cancer patients using immunohistochemistry. Low CDK5 expression was detected in 93 cases $(38.11 \%)$ and low p27 in 157 cases $(64.34 \%)$. The expression of CDK5 was significantly related to sex $(P=0.034)$ and Lauren's classification $(P=0.013)$. The expression of $p 27$ was significantly related to sex $(P=0.012)$, differentiation $(P=0.003)$, TNM stage $(P=0.013)$ and lymph node metastasis $(P=0.001)$. Based on the combined expression of CDK5 and p27, we classified the patients into four subtypes: CDK5 Low/p27 Low $(n=69)$, CDK5 High/p27 Low $(n=88)$, CDK5 Low/p27 High $(n=24)$ and CDK5 High/p27 High $(n$ $=63)$. The CDK5 Low/p27 Low expression was closely related to female $(P=0.026)$, diffuse type $(P=$ $0.027)$ and lymph node metastasis $(P=0.010)$. The CDK5 Low/p27 Low patients displayed poorer survival in comparison with the rest of the patients in Kaplan-Meier analysis. No significant overall survival difference was observed among the patients with CDK5 High and/or p27 High expression. In the multivariate analysis, CDK5 and p27 co-expression status was identified as an independent prognostic factor for patients with gastric cancer.
\end{abstract}

Key words: Gastric Cancer; CDK5; p27; Prognosis

\section{Introduction}

Gastric cancer (GC) is the second leading cause of cancer death, with East Asia accounting for more than half of the annual cases[1]. Although the incidence of gastric cancer has been declining mainly due to the increased availability of fresh fruit and vegetable and the decreased reliance on salted and preserved food[1], in 2011 there were still about 420,000 new cases diagnosed $(70 \%$ are men and $30 \%$ are women) and around 300,000 death due to this disease in China[2, 3]. Therefore, it is of great importance to find new molecular markers that will help evaluate the prognosis or develop novel therapies for gastric cancer.

Cyclin-dependent kinase $5(\mathrm{CDK} 5)$ is aprolinedirected serine/threonine kinase discovered and reported by Hellmich in 1992[4]. CDK5 has strong homology with the mammalian Cdk2 and yeast cdc2 and is an unusual molecule in the Cyclin-dependent kinases (Cdks) protein family[4]. Unlike the other Cdks, CDK5 has no known cell cycle or mitotic 
function and is not activated by cyclins[5]. Instead, CDK5 is activated via association with either of the two obligate CDK5-specific activator proteins, p35 or p39[6, 7]. Previous studies indicated that CDK5 participates in a variety of pathological and physiological functions including neuronal migration during brain development, synaptic activities in mature neurons and neuronal cell survival and death[8-10]. In neurons, the function of CDK5 as a cell cycle suppressor is independent of its kinase activity, but its nuclear localization via association with p27 (also known as KIP1)[11] and p35-mediated full assemble of the E2F1-CDK5 complex are needed[12, 13]. Recently, $C D K 5$ 's functions beyond the nervous system are emerging and increasing evidence suggested a function of $\mathrm{CDK} 5$ in cancer tumorigenesis and progression. For example, CDK5 has been implicated in the regulation of the motility and migration of prostate cancer cell lines[14], and modulation of the proliferation of medullary thyroid carcinoma and hepatocellular carcinoma cells $[15,16]$. Furthermore, elevated CDK5 activity has been detected in pancreatic and lung cancers[17, 18].

The CDK5 interacting protein p27 is a cyclin-dependent kinase inhibitor and has a central role in cell cycle regulation[19]. By getting incorporated into the CDK4/6-Cyclin D complex or the CDK2-Cyclin E/A complex, p27 restrains the G1 phase initiation and G1/S transition[20, 21]. As a critical regulator of cell cycle progression, p27 has been considered to be a tumor-suppressor gene in the conventional view[22, 23]. In studies on gastric cancers, it has been reported that p27 decreased significantly in relation to tumor progression[24]. Some studies have shown that low levels or loss of p27 expression is a significant predictor of reduced survival and tumor progression in ovary[25], breast[26],colon[27], lung[28] and liver cancers[29], However, in GC controversial roles of p27 have been reported and further research is needed to elucidate its function[30-32].

In our previous work, we have demonstrated that in GC CDK5 down regulation was an independent prognostic factor and the nuclear localization of CDK5 was critical for its tumor suppressor function[33]. Given that CDK5 nuclear localization depends on p27 in neurons, we hypothesized the functional correlation between CDK5 and p27 may affect each other's prognostic power. In the present study, we examined the expression of CDK5 and p27 in 244 gastric tumor tissues obtained from patients with resected gastric cancer and analyzed their correlation with patient clinicopathologcial features.

\section{Materials and Methods}

\section{Patients and Specimens}

The study cohort was composed of samples from 244 patients with gastric adenocarcinoma, including 180 men and 64 women (mean age, 59.4 years), who had undergone gastrectomy at the Department of Gastric Surgery, Fujian Medical University Union Hospital, between January 2009 and December 2009. Following surgery, routine chemotherapy was given to patients with advanced disease; no radiation treatment was administered to any of the patients. Eligibility criteria for this study included the following: (1) histologically proven adenocarcinoma, (2) not with other gastric tumors such as gastric stromal tumor, (3) no history of gastrectomy or other malignancy, (4) not received the neoadjuvant chemotherapy (5) availability of complete clinicopathological and survival data. The study was performed with the approval of the ethics committee of Fujian medical union Hospital. Written consent was given by the patients for their information and specimens to be stored in the hospital database and used for research.

\section{Clinicopathological and Survival Data}

The clinical and pathological data were recorded prospectively for the retrospective analysis. The clinicopathological data for the 244 gastric cancer patients included age, sex, size of primary tumor, location of primary tumor, degree of differentiation, histological type, Lauren's classification, Borrmann type, depth of invasion, lymph node metastasis, TNM stage, vessel invasion and distant metastasis. The pathologic stage of the tumor was re-assessed according to the 2010 International Union Against Cancer (UICC) on gastric cancer TNM classification (seventh edition)[34]. Overall survival was defined as the time from curative surgery to death or the last clinical follow-up. After surgery, all patients were followed every 3 months in the first 2 years, every 6 months in the next 3 years and every year afterwards or until death. The deadline for follow-up was October 2015. All patients had follow-up records for more than 5 years.

\section{Immunohistochemistry}

Paraffin blocks that contained sufficient formalin-fixed tumor specimens were serial sectioned at $4 \mu \mathrm{m}$ and mounted on silane-coated slides for immunohistochemistry analysis. The sections were deparaffinized with dimethylbenzene and rehydrated through 100, 100, 95, 85, and $75 \%$ ethanol. Antigen retrieval treatment was done in $0.01 \mathrm{~mol} / \mathrm{L}$ sodium citrate buffer (autoclaved at $121^{\circ} \mathrm{C}$ for 2 mins, pH 6.0) 
and endogenous peroxidase was blocked by incubation in $3 \% \quad \mathrm{H}_{2} \mathrm{O}_{2}$ for 10 mins at room temperature. The sections were then washed in PBS and blocked with $10 \%$ goat serum (ZhongShan Biotechnology, China) for 30 mins and incubated with rabbit anti-human CDK5 (sc-173, 1:150 dilution, Santa Cruz Biotechnology, polyclonal) or p27 (ab32034, 1:250 dilution, Abcam, monoclonal) antibody in a humidified chamber at $4^{\circ} \mathrm{C}$ overnight. Following three additional washes in PBS, the sections were incubated with HRP-conjugated secondary antibody for $30 \mathrm{mins}$ at room temperature. The visualization signal was developed with diaminobenzidine (DAB) solution and all slides were counterstained with $20 \%$ hematoxylin. Finally all slides were dehydrated and mounted on cover slips. For negative controls, the primary antibody diluent was used to replace primary antibody.

\section{Evaluation of Immunostaining Intensity}

The IHC-stained tissue sections were reviewed under microscope by 2 pathologists who were blinded to the clinical parameters, and scored independently according to the intensity of cellular staining and the proportion of stained tumor cells[35]. In cases of discrepancy, we re-evaluate the samples and a consensus score was chosen for evaluation. The criteria for the CDK5 and p27 staining score were different. The CDK5 proteins were immunohistochemically stained yellowish to brown in the cytoplasm and/or nuclei of cancer cells. The expression pattern of CDK5 was all or none in tumor tissues, suggesting the score for the proportion of stained tumor cells was unavailable. The staining intensity was scored as 0 (no staining), 1(weak staining, light yellow), 2 (moderate staining, yellow brown), and 3 (strong staining, brown) (Fig. 1A). The CDK5 protein expression was considered low if the score was 1 or less and high if it was 2 or more. Different from CDK5, p27 mainly localized in the nuclei of gastric cancer cells (235 out of 244) and its expression pattern was not either all or none. The criteria for the p27 staining were scored are as follows: the intensity score was counted as the same with CDK5 and the proportion of stained tumor cells was classified as 0 ( $\leq 5 \%$ positive cells), 1 ( $6 \%$ to $25 \%$ positive cells), 2 ( $26 \%$ to $50 \%$ positive cells) and 3 ( $\geq 51 \%$ positive cells) (Fig. 1B). The p27 protein expression was considered low if the total score (distribution score + intensity score) was 3 or less and high if it was 4 or more. The percentage of positive cells was calculated by counting the number of positive-staining cells showing immune reactivity on the cell nuclei in 10 representative high power fields.

\section{Statistical and Survival Analysis}

The IBM SPSS (SPSS, Chicago, IL) was used for all statistical analyses. The $\chi 2$ test (or the Fisher exact test) was used to analyze categorical data. Univariate survival analysis was performed using the Kaplan-Meier method, and the significance of difference between groups was analyzed using the log-rank test. The Cox proportional hazards regression model was used for multivariate survival analysis, with adjustments for variables that might be significant prognostic factors according to the univariate analysis. All $\mathrm{P}$ values were 2 -sided and statistical significance was determined at $P<0.05$.

\section{Results}

\section{Expression Status of CDK5 and p27 in Gastric Cancer}

First, we examined the CDK5 and p27 protein expression in tumor tissues from 244 gastric cancer patients using immunohistochemistry. No correlation was observed between CDK5 and p27 protein expression $(\mathrm{R}=0.173, \mathrm{p}<0.05)$. The expression of CDK5 protein was scored as low in 93(38.11\%) samples and high in 151 (61.89\%) samples. In addition, CDK5 expression was observed in the cytoplasm and nuclei of gastric cancer cells, but not in the smooth muscle, vessel or stromal fibroblast cells (Fig. 1A). The expression of p27 protein was scored as low in 157(64.34\%) samples and high in $87(35.66 \%)$ samples. Different from CDK5, p27 localized in the nuclei of gastric cancer cells(Fig. 1B). Based on the combined expression of CDK5 and p27, we classified the patients into four subtypes: CDK5 Low/p27 Low (n = 69), CDK5 High/p27 Low (n =88), CDK5 Low/p27 High $(n=24)$ and CDK5 High/p27 High $(n=63)$.

\section{Correlation between CDK5 and p27 Expression and Clinicopathological Variables}

Second, the correlation between the expression of CDK5 and p27 and the clinicopathological features are analyzed (Table 1). The expression of CDK5 was significantly related to sex $(P=0.034)$ and Lauren's classification $(P=0.013)$. Low expression of CDK5 was observed more frequently in female patients or patients with diffuse type. The expression of p27 was significantly related to sex $(P=0.012)$, differentiation $(P=0.003)$, TNM stage $(P=0.013)$ and lymph node metastasis $(P=0.001)$. Female patients or patients with high TNM stage (stages III and IV), poor differentiation, lymph node metastasis were more likely to possess lower expression of p27 (Table 1). The correlation between simultaneous low CDK5 and p27 expression and the clinicopathological features were also analyzed and the CDK5 Low/p27 Low 
expression was more often detected in female patients $(P=0.026)$, and patients with diffuse type $(P=0.027)$

(A)
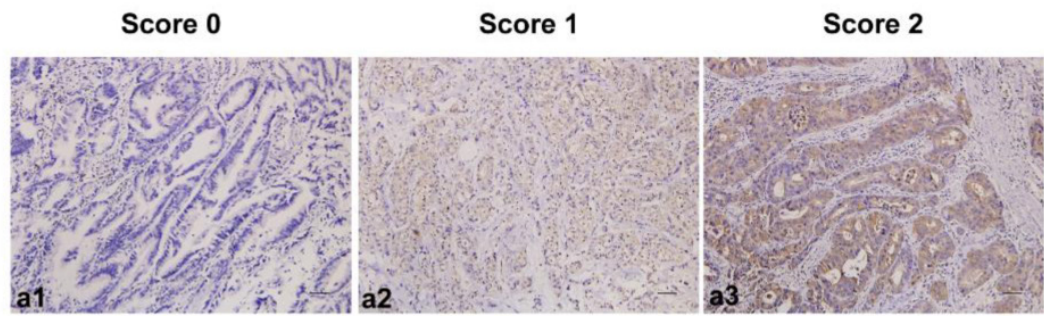

and lymph node metastasis $(P=0.010)$ (Supplementary Table 1).

20

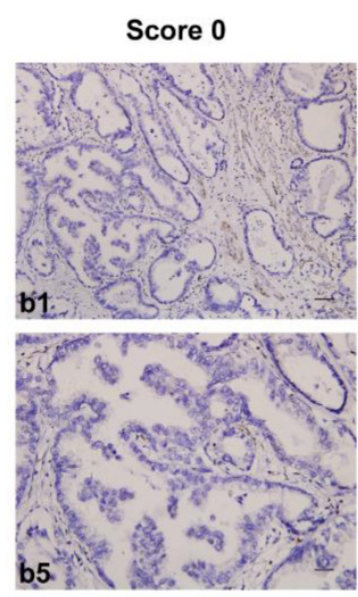

Score 1

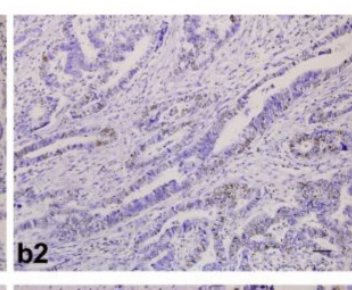

Score 2

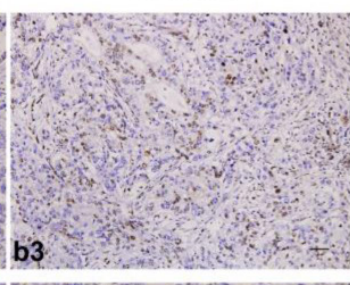

Score 3

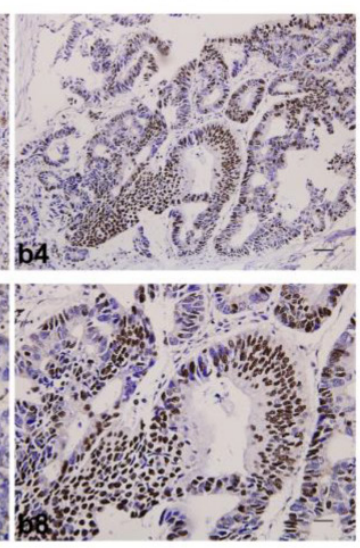

Figure 1. Immunohistochemical staining for CDK5 and p27 expression in gastric cancerous tissue and the criteria for immunohistochemistry scoring. (A) Intensity score for CDK5 expression in gastric cancer tissue. al to a4: no staining (score 0 ), weak staining (score 1), moderate staining (score 2 ) and strong staining (score 3 ). The protein expression was considered low if the score was 1 or less and high if it was 2 or more. Scale bar $=100 \mu m$. (B) Distribution and intensity score for p27 expression in gastric cancer tissue. bl to b4 (distribution score): $\leq 5 \%$ positive cells (score 0 ), $6 \%$ to $25 \%$ positive cells (score 1 ), $26 \%$ to $50 \%$ positive cells (score 2 ) and $\geq 51 \%$ positive cells (score 3). Scale bar $=100 \mu \mathrm{m}$. b5 to b8 (intensity score): no staining (score 0 ), weak staining (score 1), moderate staining (score 2 ) and strong staining (score 3 ). The protein expression was considered low if the total score (distribution score + intensity score) was 3 or less and high if it was 4 or more. Scale bar $=50 \mu \mathrm{m}$.

Table 1. Relationships between CDK5 and p27 protein expressions (immunohistochemical staining) in gastric cancer tissues and various clinicopathological variables.

\begin{tabular}{|c|c|c|c|c|c|c|c|c|c|}
\hline \multirow[t]{2}{*}{ variables } & \multirow[t]{2}{*}{ Total } & \multicolumn{4}{|c|}{ CDK5 expression } & \multicolumn{4}{|c|}{ p27 expression } \\
\hline & & low $(n=93)$ & high $(n=151)$ & $x^{2}$ & $P$ & low $(n=157)$ & high $(n=87)$ & $x^{2}$ & $P$ \\
\hline \multicolumn{10}{|l|}{ Gender } \\
\hline Male & 180 & 62 & 118 & 3.919 & $0.034^{*}$ & 108 & 72 & 5.645 & $0.012^{*}$ \\
\hline Female & 64 & 31 & 33 & & & 49 & 15 & & \\
\hline \multicolumn{10}{|c|}{ Age at surgery(yeas) } \\
\hline$\leq 60$ & 124 & 48 & 76 & 0.038 & 0.475 & 78 & 46 & 0.228 & 0.366 \\
\hline$>60$ & 120 & 45 & 75 & & & 79 & 41 & & \\
\hline \multicolumn{10}{|c|}{ Size of primary tumor $(\mathrm{cm})$} \\
\hline$\leq 5$ & 100 & 36 & 64 & 0.321 & 0.333 & 58 & 42 & 2.973 & 0.103 \\
\hline$>5$ & 144 & 57 & 87 & & & 99 & 45 & & \\
\hline \multicolumn{10}{|c|}{ Location of primary tumor } \\
\hline Lower $1 / 3$ & 57 & 22 & 35 & 1.541 & 0.673 & 35 & 22 & 1. 051 & 0.789 \\
\hline Middle $1 / 3$ & 61 & 22 & 39 & & & 42 & 19 & & \\
\hline Upper $1 / 3$ & 104 & 38 & 66 & & & 65 & 39 & & \\
\hline More than $1 / 3$ & 22 & 11 & 11 & & & 15 & 7 & & \\
\hline \multicolumn{10}{|l|}{ Borrmann type } \\
\hline early stage & 10 & 5 & 5 & 0.679 & 0.712 & 3 & 7 & 8.416 & 0.150 \\
\hline I+ II type & 90 & 33 & 57 & & & 53 & 37 & & \\
\hline III+IV type & 144 & 55 & 89 & & & 101 & 43 & & \\
\hline \multicolumn{10}{|c|}{ Degree of differentiation } \\
\hline Well/moderate & 96 & 30 & 66 & 3.162 & 0.810 & 51 & 45 & 8.683 & $0.003^{*}$ \\
\hline Poor and not & 148 & 63 & 85 & & & 106 & 42 & & \\
\hline
\end{tabular}




\begin{tabular}{|c|c|c|c|c|c|c|c|c|c|}
\hline \multirow[t]{2}{*}{ variables } & \multirow[t]{2}{*}{ Total } & \multicolumn{4}{|c|}{ CDK5 expression } & \multicolumn{4}{|c|}{ p27 expression } \\
\hline & & low $(n=93)$ & high $(n=151)$ & $x^{2}$ & $P$ & low $(n=157)$ & high $(n=87)$ & $x^{2}$ & $P$ \\
\hline Intestinal type & 196 & 67 & 129 & 6.528 & $0.013^{*}$ & 124 & 72 & 0.506 & 0.507 \\
\hline Diffuse type & 48 & 26 & 22 & & & 33 & 15 & & \\
\hline \multicolumn{10}{|c|}{ Histological type } \\
\hline Papillary & 7 & 3 & 4 & 7.011 & 0.720 & 4 & 3 & 1.768 & 0.622 \\
\hline Tubular & 189 & 64 & 125 & & & 120 & 69 & & \\
\hline Mucinous & 20 & 10 & 10 & & & 12 & 8 & & \\
\hline Signet-ring cell & 28 & 16 & 12 & & & 21 & 7 & & \\
\hline \multicolumn{10}{|c|}{ Depth of invasion } \\
\hline $\mathrm{T} 1$ & 41 & 16 & 25 & 2.082 & 0.556 & 22 & 19 & 5.793 & 0.122 \\
\hline $\mathrm{T} 2$ & 27 & 8 & 19 & & & 16 & 11 & & \\
\hline $\mathrm{T} 3$ & 62 & 21 & 41 & & & 37 & 25 & & \\
\hline $\mathrm{T} 4$ & 114 & 48 & 66 & & & 82 & 32 & & \\
\hline \multicolumn{10}{|c|}{ Lymph node metastasis } \\
\hline N0 & 64 & 24 & 40 & 4.253 & 0.235 & 33 & 31 & 17.033 & $0.001^{*}$ \\
\hline N1 & 42 & 12 & 30 & & & 20 & 22 & & \\
\hline N2 & 43 & 14 & 29 & & & 33 & 10 & & \\
\hline N3 & 95 & 43 & 52 & & & 71 & 24 & & \\
\hline \multicolumn{10}{|l|}{ TNM stage } \\
\hline I & 45 & 16 & 29 & 0.859 & 0.835 & 25 & 19 & 12.055 & $0.007^{*}$ \\
\hline II & 55 & 19 & 36 & & & 25 & 26 & & \\
\hline III & 126 & 50 & 76 & & & 87 & 31 & & \\
\hline IV & 18 & 8 & 10 & & & 20 & 11 & & \\
\hline \multicolumn{10}{|l|}{ Vessel invasion } \\
\hline Negative & 234 & 90 & 144 & & $0.746^{\mathrm{a}}$ & 153 & 81 & & $0.174^{\mathrm{a}}$ \\
\hline Positive & 10 & 3 & 7 & & & 4 & 6 & & \\
\hline \multicolumn{10}{|c|}{ Distant metastasis } \\
\hline Negative & 226 & 85 & 141 & & $0.618^{\mathrm{a}}$ & 148 & 81 & & $1.000^{\mathrm{a}}$ \\
\hline Positive & 18 & 8 & 10 & & & 12 & 6 & & \\
\hline
\end{tabular}

${ }^{*} P<0.05$ statistical significance; a: Fisher exact test.

Prognostic Value of CDK5 and p27 Expression

To elucidate the prognostic value of CDK5 and p27 expression, univariate Kaplan-Meier and multivariate Cox regression analyses were employed. Univariate analysis revealed that the overall survival was significantly associated with size and location of primary tumor, Borrmonn type, degree of differentiation, depth of invasion, lymph node metastasis, TNM stage, vessel invasion, distant metastasis, CDK5 expression and p27 expression, but not with sex, age at surgery, histological type, and Lauren's classification (Table 2) .

The 3- and 5-year cumulative survival rates were $50.5 \%$ and $40.6 \%$ for patients with low CDK5 expression, and $62.7 \%$ and $52.7 \%$ for those with high CDK5 expression. The mean survival time for patients with low and high expression of CDK5 were 40 and 75 months respectively. Clearly, gastric cancer patients with low expression of CDK5 had a poorer prognosis than those with high CDK5 expression $(\mathrm{P}<0.05)$ (Fig.2A). The 3- and 5-year cumulative survival rates were $53.2 \%$ and $42.2 \%$ for gastric cancer patients with low expression of p27, and $66.7 \%$ and $58.6 \%$ for those with high p27 expression. The mean survival time for patients with low and high expression of p27 in gastric cancer were 45.8 and 55.7 months respectively, suggesting a shorter overall survival for gastric patients with low expression of p27 $(\mathrm{P}<0.05)$ (Fig. 2B).
Next, we further evaluated the prognostic value of the combined CDK5 Low/p27 Low expression. The CDK5 Low/p27 Low patients displayed poorer survival in comparison with the rest of the patients in Kaplan-Meier analysis (Fig. 3A). The 3- and 5-year cumulative survival rates were $46.4 \%$ and $37.3 \%$, for the CDK5 Low/p27 Low patient group respectively, and $62.7 \%$ and $52.3 \%$ for the CDK5 High and /or p27 High patient groups respectively. The mean survival time was 40.3 months for patients with CDK5 Low/p27 Low, and 52.4 months for those with CDK5 High and /or p27 High (Table 2). Importantly, no significant overall survival difference was observed among the patients with CDK5 High and /or p27 High expression $(\mathrm{P}=0.335)$, suggesting the high expression of CDK5 or p27 might functionally compensate each other's low expression in prognosis (Fig. 3B).

Last, the clinicopathological parameters that were correlated with the patient survival in the univariate analysis were included in the multivariate analysis. The tumor size, vessel invasion, distant metastasis, TNM stage, depth of invasion, distant metastasis and CDK5 and p27 co-expression status were independent prognostic factors for patients with gastric cancer, whereas lymph node metastasis, tumor location, Borrmonn type and p27 expression were not (Table 3). 
Table 2. Univariate analysis of the correlation between clinicopathological parameters and survival of patients with gastric cancer

\begin{tabular}{|c|c|c|c|c|c|}
\hline \multirow[t]{2}{*}{$\begin{array}{l}\text { Clinicopathological } \\
\text { Parameters }\end{array}$} & \multicolumn{2}{|c|}{$\begin{array}{l}\text { Cumulative } \\
\text { Survival Rates, \% }\end{array}$} & \multirow{2}{*}{$\begin{array}{l}\text { Mean } \\
\text { Survival } \\
\text { Time, mo }\end{array}$} & \multirow[t]{2}{*}{$\begin{array}{l}\text { Log-Ran } \\
\text { k Test }\end{array}$} & \multirow[t]{2}{*}{$P$} \\
\hline & 3-Year & 5-Year & & & \\
\hline \multicolumn{6}{|l|}{ Gender } \\
\hline Male & 56.5 & 49.2 & 49.038 & 0.194 & 0.659 \\
\hline Female & 65.6 & 48.4 & 49.075 & & \\
\hline \multicolumn{6}{|l|}{ Age at surgery(years) } \\
\hline$\leq 60$ & 60.5 & 48.2 & 49.394 & 0.007 & 0.935 \\
\hline$>60$ & 55.5 & 47.9 & 49.285 & & \\
\hline \multicolumn{6}{|l|}{ Size of primary tumor $(\mathrm{cm})$} \\
\hline$\leq 5$ & 84.9 & 73.7 & 66.455 & 43.920 & $0.000^{*}$ \\
\hline$>5$ & 41.0 & 30.5 & 37.544 & & \\
\hline \multicolumn{6}{|l|}{ Location of primary tumor } \\
\hline Lower $1 / 3$ & 50.9 & 38.0 & 43.856 & 28.555 & $0.000^{*}$ \\
\hline Middle $1 / 3$ & 42.6 & 34.4 & 39.869 & & \\
\hline Upper $1 / 3$ & 76.8 & 67.1 & 61.639 & & \\
\hline More than $1 / 3$ & 31.8 & 22.7 & 30.500 & & \\
\hline \multicolumn{6}{|l|}{ Borrmann type } \\
\hline early stage & 90.0 & 90.0 & 72.186 & 41.538 & $0.000^{*}$ \\
\hline I+ II type & 82.1 & 71.8 & 64.855 & & \\
\hline III+IV type & 41.0 & 30.5 & 38.119 & & \\
\hline \multicolumn{6}{|l|}{ Degree of differentiation } \\
\hline Well/moderate & 70.8 & 60.3 & 57.397 & 8.872 & $0.003^{*}$ \\
\hline Poor and not & 51.1 & 40.2 & 44.104 & & \\
\hline \multicolumn{6}{|l|}{ Lauren's classification } \\
\hline Intestinal type & 57.1 & 47.4 & 48.491 & 0.389 & 0.533 \\
\hline Diffuse type & 66.1 & 50.7 & 52.764 & & \\
\hline \multicolumn{6}{|l|}{ Histological type } \\
\hline Papillary & 57.1 & 57.1 & 50.857 & 1.139 & 0.768 \\
\hline Tubular & 56.1 & 48.7 & 48.362 & & \\
\hline Mucinous & 75.0 & 53.6 & 53.850 & & \\
\hline Signet-ring cell & 59.4 & 48.3 & 50.384 & & \\
\hline Depth of invasion & & & & & \\
\hline $\mathrm{T} 1$ & 97.6 & 95.1 & 78.026 & 63.910 & $0.000^{*}$ \\
\hline $\mathrm{T} 2$ & 88.9 & 74.1 & 67.889 & & \\
\hline T3 & 59.2 & 46.0 & 48.764 & & \\
\hline $\mathrm{T} 4$ & 37.7 & 28.1 & 34.532 & & \\
\hline Lymph node metastasis & & & & & \\
\hline No & 89.1 & 81.1 & 70.069 & 60.383 & $0.000^{*}$ \\
\hline N1 & 68.5 & 68.5 & 60.550 & & \\
\hline N2 & 58.1 & 34.9 & 43.674 & & \\
\hline N3 & 34.7 & 23.1 & 32.733 & & \\
\hline TNM stage & & & & & \\
\hline I & 97.7 & 95.4 & 77.884 & 75.213 & $0.000^{*}$ \\
\hline II & 80.1 & 64.1 & 62.812 & & \\
\hline III & 44.1 & 31.3 & 39.543 & & \\
\hline IV & 25.8 & 16.1 & 23.849 & & \\
\hline Vessel invasion & & & & & \\
\hline Negative & 59.7 & 49.3 & 50.412 & 8.268 & $0.004^{*}$ \\
\hline Positive & 20.0 & 20.0 & 23.400 & & \\
\hline Distant metastasis & & & & & \\
\hline Negative & 60.5 & 50.6 & 51.444 & 20.096 & $0.000^{*}$ \\
\hline Positive & 27.8 & 16.7 & 22.518 & & \\
\hline CDK5 expression & & & & & \\
\hline Low & 50.5 & 40.6 & 40.000 & 5.373 & $0.020^{*}$ \\
\hline High & 62.7 & 52.7 & 75.000 & & \\
\hline p27 expression & & & & & \\
\hline Low & 53.3 & 42.2 & 45.796 & 5.953 & $0.015^{*}$ \\
\hline High & 66.7 & 58.6 & 55.718 & & \\
\hline CDK5/p27 expression & & & & & \\
\hline CDK5 Low /p27 Low & 46.4 & 37.3 & 40.323 & 10.291 & $0.016^{*}$ \\
\hline CDK5 High/p27 Low & 58.8 & 46.1 & 49.153 & & \\
\hline CDK5 Low /p27 High & 62.5 & 50.0 & 51.500 & & \\
\hline CDK5 High/p27 High & 68.3 & 61.9 & 57.343 & & \\
\hline CDK5/p27 expression & & & & & \\
\hline CDK5 Low /p27 Low & 46.4 & 37.3 & 40.323 & 8.352 & $0.004^{*}$ \\
\hline CDK5 high and/or p27 high & 62.7 & 52.3 & 52.435 & & \\
\hline
\end{tabular}
detected in $93(38.11 \%)$ samples and low expression of p27 protein was detected in $157(64.34 \%)$ samples. Samples with simultaneous low expression of CDK5 and p27 were 69 (28.3\%). The CDK5 Low/p27 Low expression was related to sex, Lauren's classification and lymph node metastasis, which indicated that a decrease in both CDK5 and p27 protein expression may cause advancing disease in patients with GC. In univariate analyses, low CDK5 expression, low p27 expression and CDK5 Low/p27 Low expression were found to be closely associated with poor survival among patients with GC (Table 2). In multivariate analysis, the combined CDK5/p27 expression turned out to be an independent prognostic predictor for GC patients (Table 3).

Increasing evidence demonstrated uncontrolled gastric cancer cell growth is due to disruption of the G1/S and G2/M checkpoints, which involved a series of positive and negative cell-cycle regulators[36, 37]. Zhang et al. found that CDK5 could function as a cell cycle suppressor when it localized in the nucleus in neurons[12]. However, CDK5 has no intrinsic nuclear localization signal. Its nuclear localization relies on its binding to p27 in neurons[11]. We previously discovered that nuclear CDK5 suppressed GC cell proliferation and xenograft growth independent of its kinase activity, but dependent on its association with p27[33]. As a cyclin-dependent kinase inhibitor, p27 could negatively modulate cell cycle progression through inhibition of the G2/M phase[38] and its prognostic value in GC had been reported[39, 40]. But no studies have examined the prognostic roles of the combination of CDK5 and p27 in GC. In this study, we discovered that CDK5 or p27 expression were associated with patient survival, which is consistent with our previous study and other reports. When CDK5 and p27 expression are combined, not surprisingly, the CDK5 Low/p27 Low patient group displayed a shorter overall survival than other patients (Fig 3A). However, no significant overall survival difference was observed among the patients with CDK5 High and /or p27 High expression (Fig. 3B). Further analysis revealed that in patients with high CDK5 expression, the expression of p27 was no longer associated with overall survival (Log Rank test, $P=0.139$ ). Similarly, in patients with high p27 expression, the expression of CDK5 was not associated with overall survival either (Log Rank test, $P=0.475)$. Taken together, our data suggested that the tumor suppressive functions of CDK5 and p27 were closely related. The high expression of one may 
compensate for the loss or down regulation of another. Thus the co-expression profile of CDK5 and

(A)

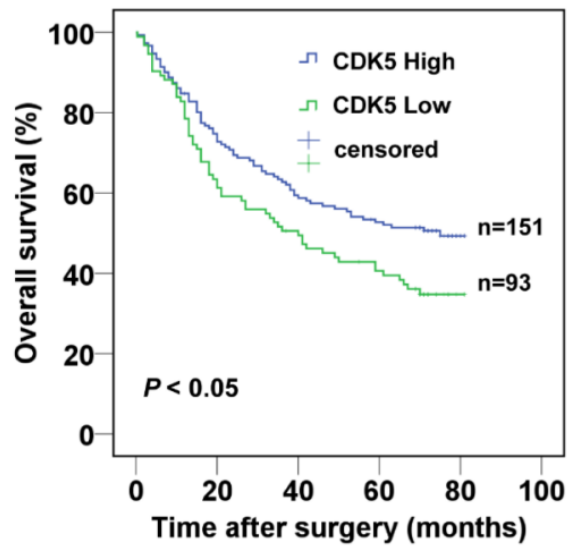

p27 as a prognostic marker will probably provide more accurate prediction in clinical practice.

(B)

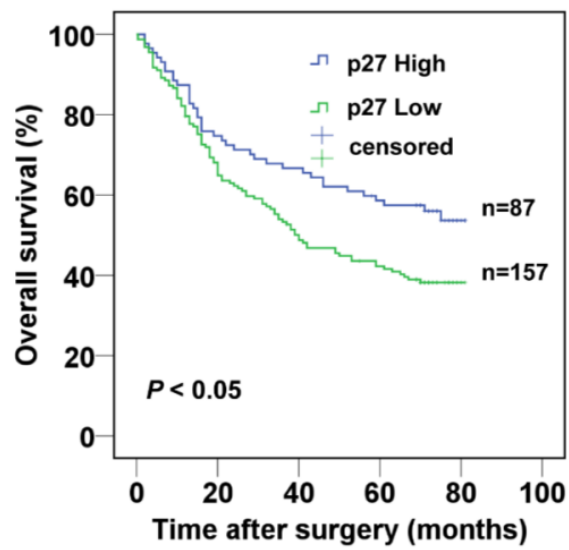

Figure 2. Kaplan-Meier analysis of the correlation between the expression of (A) CDK5 and (B) p27 and the overall survival of gastric cancer patients.

(A)

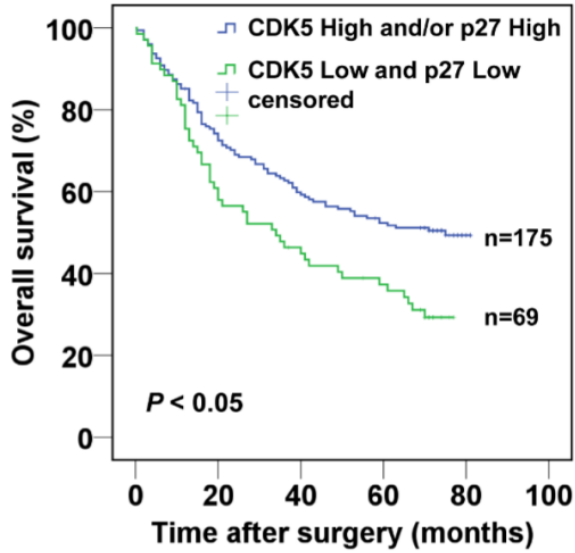

(B)

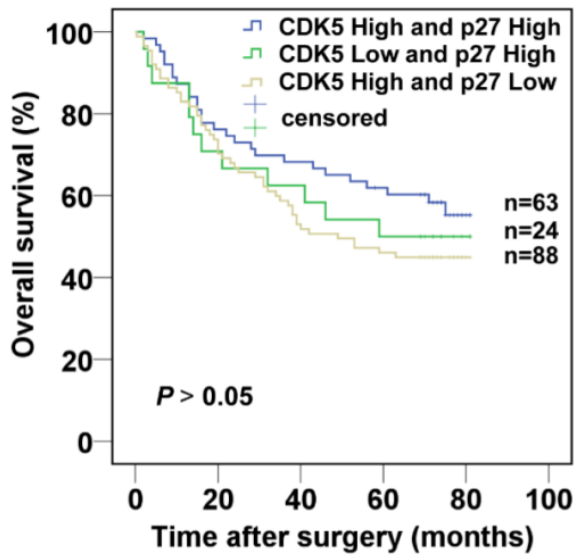

Figure 3. Kaplan-Meier analysis of the correlation between the combined CDK5 and p27 expression and the overall survival of gastric cancer patients.(A) Patients with low expression of both CDK5 and p27 were compared with the rest of the patients.(B) Patients with CDK5 high and/or p27 high expression were subject to analysis.

Table 3. Multivariate analysis of the correlation between clinicopathological parameters and survival time of patients with gastric cancer

\begin{tabular}{|c|c|c|c|c|c|}
\hline Covariates & Coefficient & Standard Error & HR & 95\% CI for HR & $P$ \\
\hline Tumor location (cardia vs. others) & N.A. & N.A. & N.A. & N.A. & N.A. \\
\hline Tumor size $(\geq 5$ vs. $<5 \mathrm{~cm})$ & 0.466 & 0.231 & 1.593 & $1.013-2.504$ & $0.044^{*}$ \\
\hline Lymph node metastasis (positive vs. negative) & N.A. & N.A. & N.A. & N.A. & N.A. \\
\hline Vessel invasion (positive vs. negative) & 0.765 & 0.369 & 2.148 & $1.042-4.431$ & $0.038^{*}$ \\
\hline Distant metastasis (positive vs. negative) & 0.715 & 0.281 & 2.044 & $1.179-3.543$ & $0.011^{*}$ \\
\hline Depth of invasion (T3,T4 vs. T1,T2) & 1.047 & 0.385 & 2.849 & $1.338-6.064$ & $0.007^{*}$ \\
\hline TNM stage (stage III and IV vs. I and II) & 0.619 & 0.284 & 1.856 & $1.063-3.241$ & $0.030^{*}$ \\
\hline $\begin{array}{l}\text { CDK5 and p27 expression (low/low vs. high } \\
\text { and/or high) }\end{array}$ & 0.395 & 0.183 & 1.485 & $1.037-2.127$ & $0.031^{*}$ \\
\hline Borrmann type (type early,I,II vs. III,IV) & N.A. & N.A. & N.A. & N.A. & N.A. \\
\hline
\end{tabular}

HR: hazard ratio; $\mathrm{CI}$ : confidence interval; ${ }^{*} P<0.05$, statistical significance: N.A.: not available

We also found that the CDK5 Low/p27 Low expression was associated with lymph node metastasis in GC (Supplementary table 1). This suggested that the identification of CDK5 Low/p27 Low expression in preoperative mucosal biopsies from GC patients might indicate the necessity for a more aggressive lymphadenectomy, albeit further studies in a larger cohort of patients are needed. In addition, considering the inferior prognosis of the CDK5 Low/p27 Low patients, more frequent 
follow-ups are probably needed for these patients after surgery.

In summary, co-expression of CDK5 and p27 is an independent prognostic factor for overall survival in patients with gastric cancer. Immunohistochemical analysis of CDK5 and p27 protein expression on preoperative biopsies and cancer tissues after surgery may aid in stratifying patient treatment algorithms and predicting GC patient outcome.

\section{Supplementary Material}

Table S1. http:/ /www.jcancer.org/v07p1049s1.pdf

\section{Acknowledgments}

This work was supported by National Natural Science Foundation of China (81441123 to Chang-Ming Huang), National Key Clinical Specialty Discipline Construction Program of China (No.[2012]649), Key Scientific and Technological Project of Fujian Province, China (2014Y0025 to Chang-Ming Huang), Natural Science Foundation of Fujian Province, China ( 2014J01322 to Jian-Wei Xie) and National Natural Science Foundation of China for Young Scholar (31301172 to Yao Lin).

\section{Competing interests}

The authors have disclosed that they have no significant relationships with, or financial interest in, any commercial companies pertaining to this article.

\section{References}

1. Jemal A, Bray F, Center MM, Ferlay J, Ward E, Forman D. Global cancer statistics. CA: a cancer journal for clinicians. 2011; 61: 69-90.

2. Yang L. Incidence and mortality of gastric cancer in China. World Journal of Gastroenterology. 2006; 12: 17.

3. Chen $\mathrm{W}$, Zheng R, Zeng $\mathrm{H}$, Zhang $\mathrm{S}$. The updated incidences and mortalities of major cancers in China, 2011. Chinese journal of cancer. 2015; 34: 53 .

4. Hellmich MR, Pant HC, Wada E, Battey JF. Neuronal cdc2-like kinase: a cdc2-related protein kinase with predominantly neuronal expression. Proceedings of the National Academy of Sciences of the United States of America. 1992; 89: 10867-71.

5. Dhavan R, Tsai LH. A decade of CDK5. Nature reviews Molecular cell biology. 2001; 2: 749-59.

6. Lew J, Huang QQ, Qi Z, Winkfein RJ, Aebersold R, Hunt T, et al. A brain-specific activator of cyclin-dependent kinase 5. Nature. 1994; 371: 423-6.

7. Tsai LH, Delalle I, Caviness VS, Jr., Chae T, Harlow E. p35 is a neural-specific regulatory subunit of cyclin-dependent kinase 5. Nature. 1994; 371: 419-23.

8. Cruz JC, Tsai LH. A Jekyll and Hyde kinase: roles for Cdk5 in brain development and disease. Current opinion in neurobiology. 2004; 14: 390-4.

9. Hawasli $\mathrm{AH}, \mathrm{Bibb} \mathrm{JA}$. Alternative roles for $\mathrm{Cdk} 5$ in learning and synaptic plasticity. Biotechnology journal. 2007; 2: 941-8.

10. Hisanaga S, Endo R. Regulation and role of cyclin-dependent kinase activity in neuronal survival and death. Journal of neurochemistry. 2010; 115: 1309-21.

11. Zhang J, Li H, Herrup K. Cdk5 nuclear localization is p27-dependent in nerve cells: implications for cell cycle suppression and caspase- 3 activation. The Journal of biological chemistry. 2010; 285: 14052-61.

12. Zhang J, Li H, Yabut O, Fitzpatrick H, D'Arcangelo G, Herrup K. Cdk5 suppresses the neuronal cell cycle by disrupting the E2F1-DP1 complex. The Journal of neuroscience : the official journal of the Society for Neuroscience. 2010; 30: 5219-28.

13. Zhang J, Herrup K. Cdk5 and the non-catalytic arrest of the neuronal cell cycle. Cell Cycle. 2008; 7: 3487-90

14. Strock CJ, Park JI, Nakakura EK, Bova GS, Isaacs JT, Ball DW, et al. Cyclin-dependent kinase 5 activity controls cell motility and metastatic potential of prostate cancer cells. Cancer Res. 2006; 66: 7509-15.

15. Pozo K, Castro-Rivera E, Tan C, Plattner F, Schwach G, Siegl V, et al. The role of Cdk5 in neuroendocrine thyroid cancer. Cancer cell. 2013; 24: 499-511.
16. Ehrlich SM, Liebl J, Ardelt MA, Lehr T, De Toni EN, Mayr D, et al. Targeting cyclin dependent kinase 5 in hepatocellular carcinoma--A novel therapeutic approach. Journal of hepatology. 2015; 63: 102-13.

17. Feldmann G, Mishra A, Hong SM, Bisht S, Strock CJ, Ball DW, et al. Inhibiting the cyclin-dependent kinase CDK5 blocks pancreatic cancer formation and progression through the suppression of Ras-Ral signaling. Cancer Res. 2010; 70: 4460-9.

18. Demelash A, Rudrabhatla P, Pant HC, Wang X, Amin ND, McWhite CD, et al. Achaete-scute homologue-1 (ASH1) stimulates migration of lung cancer cells through Cdk5/p35 pathway. Molecular biology of the cell. 2012; 23: 2856-66.

19. Polyak K, Lee MH, Erdjument-Bromage H, Koff A, Roberts JM, Tempst P, et al. Cloning of p27Kip1, a cyclin-dependent kinase inhibitor and a potential mediator of extracellular antimitogenic signals. Cell. 1994; 78: 59-66.

20. Ladha MH, Lee KY, Upton TM, Reed MF, Ewen ME. Regulation of exit from quiescence by p27 and cyclin D1-CDK4. Molecular and cellular biology. 1998; 18: $6605-15$

21. Ray A, James MK, Larochelle S, Fisher RP, Blain SW. p27Kip1 inhibits cyclin D-cyclin-dependent kinase 4 by two independent modes. Molecular and cellular biology. 2009; 29: 986-99.

22. Fero ML, Randel E, Gurley KE, Roberts JM, Kemp CJ. The murine gene p27Kip1 is haplo-insufficient for tumour suppression. Nature. 1998; 396: 177-80.

23. Philipp-Staheli J, Payne SR, Kemp CJ. p27(Kip1): regulation and function of a haploinsufficient tumor suppressor and its misregulation in cancer. Experimental cell research. 2001; 264: 148-68.

24. Yasui W, Kudo Y, Semba S, Yokozaki H, Tahara E. Reduced Expression of Cyclin-dependent Kinase Inhibitor p27Kipl Is Associated with Advanced Stage and Invasiveness of Gastric Carcinomas. Japanese journal of cancer research. 1997; 88: 625-9.

25. Bali A, O'Brien PM, Edwards LS, Sutherland RL, Hacker NF, Henshall SM. Cyclin D1, p53, and p21Waf1/Cip1 expression is predictive of poor clinical outcome in serous epithelial ovarian cancer. Clinical cancer research : an official journal of the American Association for Cancer Research. 2004; 10: 5168-77.

26. Nohara T, Ryo T, Iwamoto S, Gon G, Tanigawa N. Expression of cell-cycle regulator p27 is correlated to the prognosis and ER expression in breast carcinoma patients. Oncology. 2001; 60: 94-100.

27. Ogino S, Shima K, Nosho K, Irahara N, Baba Y, Wolpin BM, et al. A cohort study of p27 localization in colon cancer, body mass index, and patient survival. Cancer epidemiology, biomarkers \& prevention : a publication of the American Association for Cancer Research, cosponsored by the American Society of Preventive Oncology. 2009; 18: 1849-58.

28. Zhuang Y, Yin HT, Yin XL, Wang J, Zhang DP. High p27 expression is associated with a better prognosis in East Asian non-small cell lung cancer patients. Clinica chimica acta; international journal of clinical chemistry. 2011; 412: 2228-31.

29. Chetty R. p27 Protein and cancers of the gastrointestinal tract and liver: an overview. Journal of clinical gastroenterology. 2003; 37: 23-7.

30. Wiksten JP, Lundin J, Nordling S, Kokkola A, von Boguslawski K, Haglund C. The prognostic value of p27 in gastric cancer. Oncology. 2002; 63: 180-4.

31. So JB, Samarasinge K, Raju GC, Moochhala SM, Ti TK. Expression of cell-cycle regulators p27 and cyclin E correlates with survival in gastric carcinoma patients. The Journal of surgical research. 2000; 94: 56-60.

32. Feakins RM, Mulcahy HE, Quaglia A, Jawhari A, Zhang Z, Patchett SE. p27(Kip1) loss does not predict survival in patients with advanced gastric carcinoma. Cancer. 2000; 89: 1684-91.

33. Cao L, Zhou J, Zhang J, Wu S, Yang X, Zhao X, et al. Cyclin-dependent kinase 5 decreases in gastric cancer and its nuclear accumulation suppresses gastric tumorigenesis. Clinical cancer research : an official journal of the American Association for Cancer Research. 2015; 21: 1419-28.

34. Wittekind C. [2010 TNM system: on the 7th edition of TNM classification of malignant tumors]. Der Pathologe. 2010; 31: 331-2

35. Shou ZX, Jin X, Zhao ZS. Upregulated expression of ADAM17 is a prognostic marker for patients with gastric cancer. Annals of surgery. 2012; 256: 1014-22.

36. Kim SJ, Lee HW, Baek JH, Cho YH, Kang HG, Jeong JS, et al. Activation of nuclear PTEN by inhibition of Notch signaling induces G2/M cell cycle arrest in gastric cancer. Oncogene. 2015

37. Yang M, Zhong J, Zhao M, Wang J, Gu Y, Yuan X, et al. Overexpression of nuclear apoptosis-inducing factor 1 altered the proteomic profile of human gastric cancer cell MKN45 and induced cell cycle arrest at G1/S phase. PloS one. 2014; 9: e100216.

38. Yuan CX, Zhou ZW, Yang YX, He ZX, Zhang X, Wang D, et al Danusertib, a potent pan-Aurora kinase and ABL kinase inhibitor, induces cell cycle arrest and programmed cell death and inhibits epithelial to mesenchymal transition involving the PI3K/Akt/mTOR-mediated signaling pathway in human gastric cancer AGS and NCI-N78 cells. Drug design, development and therapy. 2015; 9: 1293-318.

39. Zhang G, Cheng Y, Chen G, Tang Y, Ardekani G, Rotte A, et al. Loss of tumor suppressors KAI1 and p27 identifies a unique subgroup of primary melanoma patients with poor prognosis. Oncotarget. 2015; 6: 23026-35.

40. Aoyagi K, Kouhuji K, Miyagi M, Imaizumi T, Kizaki J, Isobe T, et al. Expression of p27Kip1 protein in gastric carcinoma. Hepato-gastroenterology. 2013; 60: 390-4. 